\title{
Investigation of Curing Process on Melt Spun Polymethylsilsesquioxane Fiber as Precursor for Silicon Oxycarbide Fibers
}

\author{
Masaki Narisawa ${ }^{1, a}$, Ryu-Ichi Sumimoto ${ }^{1, b}$, Ken-Ichiro Kita ${ }^{1, c}$, Hiroshi \\ Mabuchi $^{1, ~ d, ~ Y o u n g-W o o k ~ K i m ~}{ }^{2, ~ e}$, Masaki Sugimoto, ${ }^{3, f}$, Masahito Yoshikawa, \\ ${ }^{1}$ Graduate School of Engineering, Osaka Prefecture University, 1-1 Gakuen-Cho, Naka-Ku, Sakai \\ 599-8531, Japan \\ ${ }^{2}$ Department of Materials Science and Engineering, The University of Seoul, 90 Jeonnong-dong, \\ Dongdaemoon-ku, Seoul 130-743, Korea \\ ${ }^{3}$ Quantum Beam Science Directorate, Japan Atomic Energy Agency, Takasaki, Gunma, 370-1292, \\ Japan

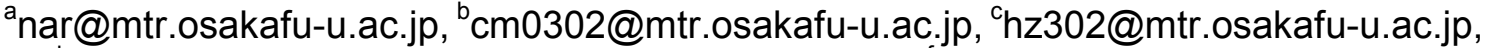 \\ dmabuchi@mtr.osakafu-u.ac.jp, ${ }^{\mathrm{d}}$ ywkim@uos.ac.kr, ${ }^{f}$ sugimoto.masaki@jaea.go.jp, \\ gyoshikawa.masahito@jaea.go.jp
}

Keywords: Precursor method, ceramic fiber, silicon oxycarbide, melt spinning, metal chloride vapor, electron beam irradiation

\begin{abstract}
Polymethylsilsesquioxane (PMSQ) fiber was exposed to metal chloride vapors in a controlled atmosphere or electron beam irradiation in air to promote the curing process. The cured fibers were pyrolyzed at $1273 \mathrm{~K}$ to compare the efficiency of individual curing method. The cured fibers were investigated by FT-IR, an optical microscope and TG analysis. In the case of successful curing, averaged diameter and tensile strength were analyzed on the obtained Si-O-C fibers.
\end{abstract}

\section{Introduction}

A number of siloxane backbone polymers (silicone resin) have been investigated as a binding agent in balk ceramic materials, matrix source of ceramic matrix composites, and starting precursors for ceramic porous bodies or coatings [1-4]. Application of such silicone resins for ceramic fiber precursor is, however, rare except the early try of Hurwitz in 1980s [1]. In general, heat resistance of $\mathrm{Si}-\mathrm{O}-\mathrm{C}$ derived from such silicone resins is believed to be far lower than that of Si-C or Si-exC. Estimation of oxidation resistance on the Si-O-C materials, however, suggested that the resistance strongly depended on carbon content and a number of $\mathrm{Si}-\mathrm{C}$ bond remained in the pyrolyzed materials [5]. Reported long life time at $1473 \mathrm{~K}$ is sufficiently promising as heat insulators and corrosion resistant filters available at high temperature. Simple chemical composition with silicon, carbon and oxygen without special elements is also attractive for industrial uses.

Since the materials utility will be limited in the conventional industry, starting precursor for Si-O-C (with low carbon content) must satisfy a factor of low cost. From such economical viewpoint, a polymer called polymethylsilsesquioxane (PMSQ) is most promising candidate for Si-O-C precursor. $\mathrm{CH}_{3} \mathrm{SiCl}_{3}$, which is a starting monomer for $\mathrm{PMSQ}$, is major sub product of classic Rochow process [6]. It means that $\mathrm{CH}_{3} \mathrm{SiCl}_{3}$ is naturally supplied in a mass scale in silicone industry, and intrinsic cost of PMSQ can be reduced to quite low.

Here, we report evaluations of melt spinnability and effective curing process of PMSQ. Since the softening point of PMSQ is low, curing on the spun fiber was performed at vicinity of room temperature by using metal chloride vapor or electron beam irradiation [7,8]. Effect of the curing method on obtained Si-O-C fibers was investigated. In successful cases, tensile tests were performed on pyrolyzed fibers. Preliminary estimation of heat resistivity of Si-O-C fibers was performed by exposing the fibers on flame of a gas-oxygen burner. 


\section{Experimental}

Polymethylsilsesquioxane (YR 3370, Momentive Performance Materials Japan) in a form of a transparent solid was prepared for melt spinning process. Since various PMSQ with different molecular structure (First PMSQ soluble in organic solvent was synthesized in 1978 [9,10]) is available in industry, molecular structure, ceramization process and viscoelastic properties of the used PMSQ must be characterized in detail. These data have been shown in our previous studies [11,12]. The precursor was melt spun to fiber form at 403-453K. The diameters of the spun fibers were measured by Digital Microscope. For the chemical vapor curing, exposure of spun fibers to $\mathrm{SiCl}_{4}$, $\mathrm{TiCl}_{4}$ or $1.0 \mathrm{M} \mathrm{BCl}_{3}$ in para-xylene solution at $299-309 \mathrm{~K}$ was examined (Fig. 1). The electron beam curing was performed with $2 \mathrm{MeV}$ beam with a dose rate of $0.79 \mathrm{kGy} / \mathrm{s}$. FT-IR spectra and TG curves on the cured fibers were analyzed. After the pyrolysis at $1273 \mathrm{~K}$, morphology of the fibers was observed by FE-SEM. In the cases of the $\mathrm{SiCl}_{4}$ curing and electron beam curing, tensile strength of the resulting monofilaments was measured with a gauge length of $10 \mathrm{~mm}$. Morphology change of the obtained Si-O-C fibers after high temperature

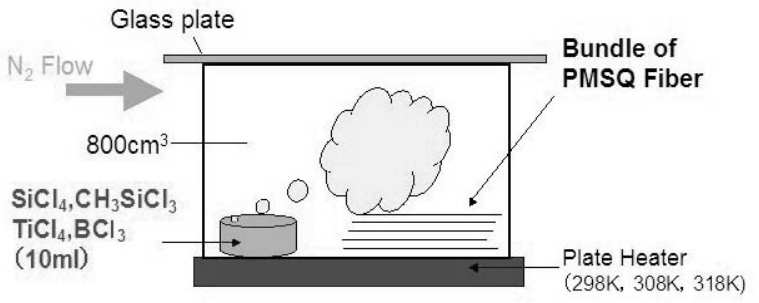
exposure was observed by FE-SEM.

\section{Results and Discussion}

Melt spinning process was successful at $403-453 \mathrm{~K}$ with a spinning speed of $10 \mathrm{~m} / \mathrm{s}$ (Fig. 2). The averaged diameter of the spun fibers depended on melt spinning temperature and holding time (Table 1). As the temperature rising, melt spinnability of PMSQ was improved. Beyond 423K, however, melt hardening started to prevent the spinning process, and averaged diameter of the fiber became to be dispersed. It is consistent with reported thermosetting character of PMSQ. In order to diminish such melt hardening effect, reduction of holding time at appointed melt spinning temperature was effective.

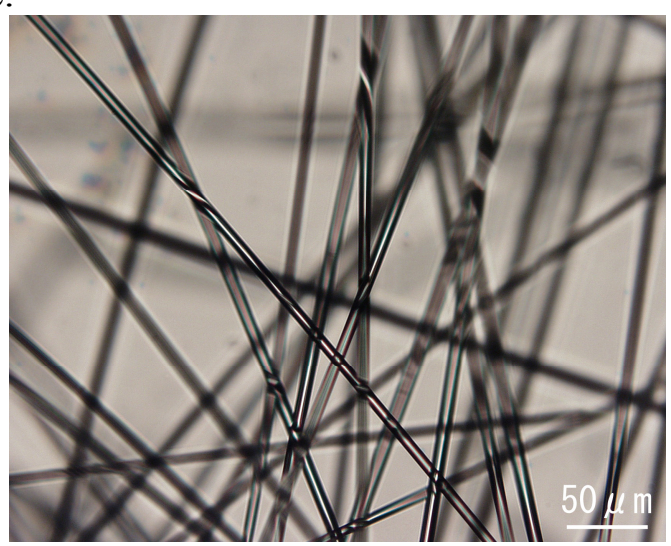

Table 1. An averaged diameters of melt spun PMSQ fiber.

\begin{tabular}{c|c|c}
\hline Mett Spinning Temperature & Holding Time & Averaged Diameter \\
\hline $403 \mathrm{~K}$ & $60 \mathrm{~min}$ & $30.0 \pm 7.1 \mu \mathrm{m}$ \\
$423 \mathrm{~K}$ & $60 \mathrm{~min}$ & $25.4 \pm 4.2 \mu \mathrm{m}$ \\
$423 \mathrm{~K}$ & $20 \mathrm{~min}$ & $16.8 \pm 1.4 \mu \mathrm{m}$ \\
$453 \mathrm{~K}$ & $60 \mathrm{~min}$ & $51.7 \pm 6.4 \mu \mathrm{m}$ \\
\hline
\end{tabular}

Fig. 2. An optical micrograph of melt spun PMSQ fiber.

Since softening temperature of PMSQ is low, thermal oxidation curing usually adopted for PCS fiber is not available for PMSQ. Curing by $\mathrm{SiCl}_{4}$ or $\mathrm{BCl}_{3}$ vapors at room temperature were available for keeping fiber form after pyrolysis. In the case of $\mathrm{TiCl}_{4}$ vapor, higher temperature, $543 \mathrm{~K}$, was necessary to perform the curing. It is probably due to low vapor pressure of $\mathrm{TiCl}_{4}$ as compared with $\mathrm{SiCl}_{4}$ and $\mathrm{BCl}_{3}$. The fiber surface, cured with $\mathrm{BCl}_{3}$ or $\mathrm{TiCl}_{4}$ was, however, covered by oxide base particles (Fig. 3. (a), (b), (c)). The particles sometimes made bridges between monofilaments. In these cases, tensile tests on monofilaments were impossible. The fiber obtained with $\mathrm{SiCl}_{4}$ curing and $1273 \mathrm{~K}$ pyrolysis showed smooth surface and tensile tests on monofilaments were possible. The averaged strength was $0.30 \pm 0.13 \mathrm{GPa}$. 

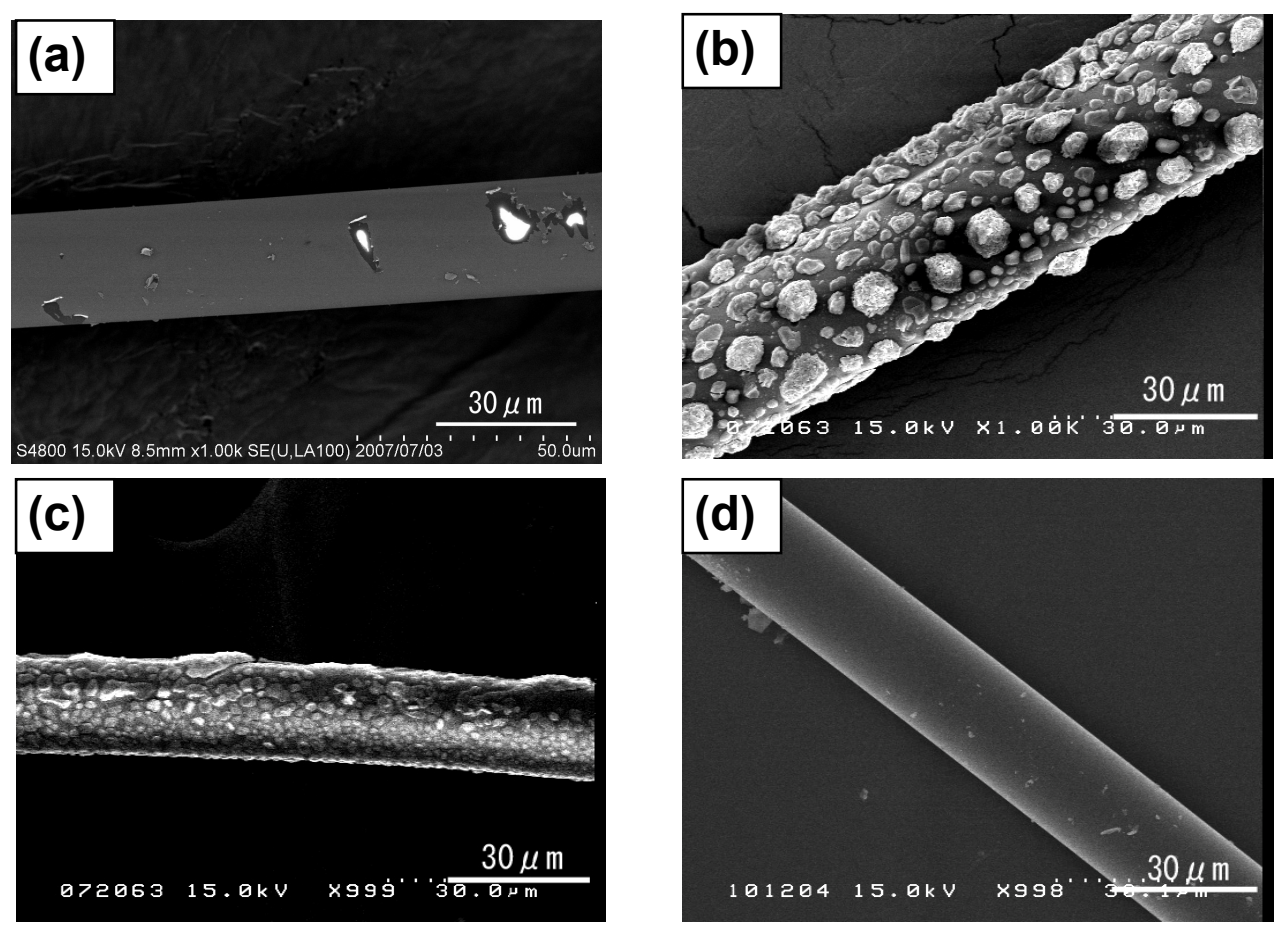

Fig. 3. SEM images of Si-O-C (or Si-O-C-M) fibers after $1273 \mathrm{~K}$ pyrolysis: (a) $\mathrm{SiCl}_{4}$ curing, (b) TiCl4 curing, (c) BCl3 curing and (d) Electron beam curing.

Electron beam curing in an air flow was also available for curing (Fig. 3. (d)). Although use of the electron beam curing is not appropriate for our final purpose to produce low cost fiber, it is useful probe to investigate theoretical properties of Si-O-C fibers derived from PMSQ. The measured mechanical properties of the fiber strongly depended not only on spun diameter, but also on total dose of irradiation (Fig. 4). At total dose with $10.3 \mathrm{MGy}$, the tensile strength of the fiber showed maximum of $0.73 \pm 0.28 \mathrm{GPa}$ with an averaged diameter of $16.8 \mu \mathrm{m}$.

Figure 5 shows the micrographs of the obtained Si-O-C fibers (with $\mathrm{SiCl}_{4}$ curing) after exposure for oxygen-gas burner. These images are compared with that of high purity silica fibers after exposure. Even after 20min exposure, the Si-O-C showed slight fusion, while pure silica fibers were completely melted down just after 10 sec.
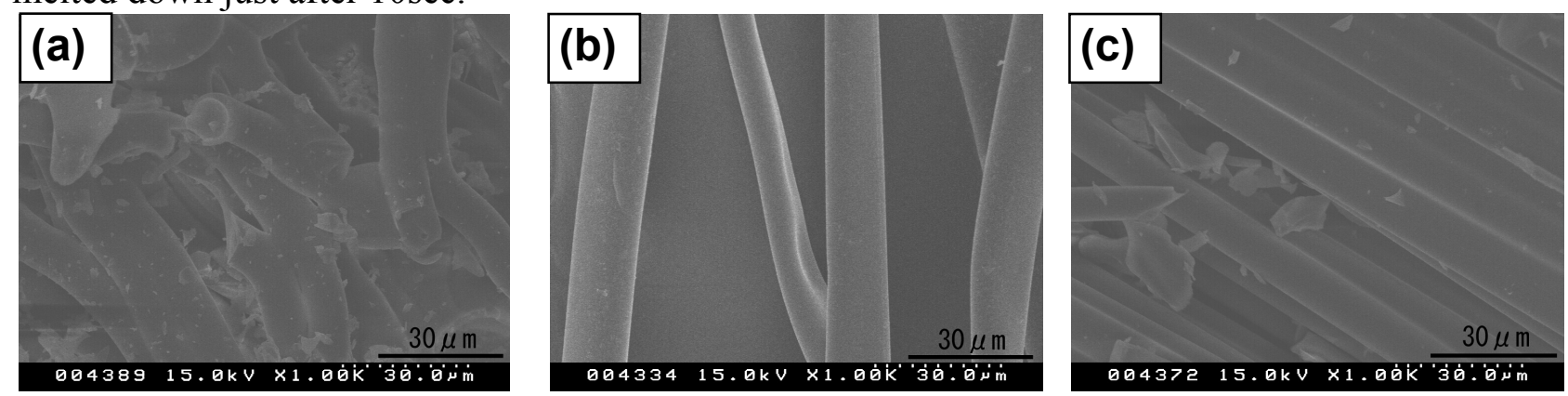

Fig. 5. SEM images of $\mathrm{SiO}_{2}$ fiber or Si-O-C fiber ( $\mathrm{SiCl}_{4}$ curing) after oxygen-gas flame exposure: (a) $\mathrm{SiO}_{2}$ fiber after $10 \mathrm{~s}$ exposure, (b) Si-O-C fiber after $1 \mathrm{~min}$ exposure, (c) Si-O-C fiber after 20 min exposure. 


\section{Summary}

The average and distribution of spun PMSQ fiber diameter are strongly influenced by melt spinning temperature and holding time. Tendency is consistent with the reported thermosetting character of PMSQ. The vapors of $\mathrm{SiCl}_{4}$ and $1.0 \mathrm{M} \mathrm{BCl}_{3}$ in $\mathrm{p}$-xylene solution are effective for curing even at room temperature. In a case of $\mathrm{TiCl}_{4}$, higher temperature $309 \mathrm{~K}$ is required. The tensile strength measurement is possible only in the case of $\mathrm{SiCl}_{4}$, and the obtained value at present is $0.30 \pm 0.13 \mathrm{GPa}$. Electron beam curing in an air flow is also effective to perform the fiber curing. In this case, the strength of $0.73 \pm 0.28 \mathrm{GPa}$ is obtained with a total dose of $10.3 \mathrm{MGy}$. The heat resistivity of obtained $\mathrm{Si}-\mathrm{O}-\mathrm{C}$ fiber is far higher than that of pure silica fiber.

\section{Acknowledgement}

This work is partly supported by a Grant-in Aid for Scientific Research C (No. 20560627) from Japan Society of Promotion Science.

\section{References}

[1] F.I. Hurwitz, L. Hyatt, L. Gorecki and L.D. Amore: Ceram. Eng. Sci. Proc. Vol. 8 (1987), p. 732

[2] F.I. Hurwitz, P. Heiman, S.C. Farmer and D.M. Hembree: J. Mater. Sci. Vol. 28 (1993), p. 6622

[3] P. Greil: J. Am. Ceram. Soc. Vol. 78 (1995), p. 855

[4] Y.W. Kim, S.H. Kim, X. Xu, C.H. Choi, C.B. Park and H.D. Kim: J. Mater. Sci. Lett. Vol. 21 (2002), p. 1667

[5] C.M. Brewer, D.R. Bujalski, V.E. Parent, K. Su and G.A. Zank: J. Sol-Gel Sci. Tech. Vol. 14 (1999), p. 49

[6] E.G. Rochow: Silicon and Silicones (Springer-Verlag, Berlin, 1987).

[7] K. Okamura and T. Seguchi: J. Inorg. Organomet. Polym. Vol. 2 (1992), p. 171

[8] P. Baldus, M. Jansen and D. Sporn: Science Vol. 285, p. 699

[9] T. Suminoe, Japan Patent 88099. (1978)

[10] R.H. Baney, M. Itoh, A. Sakakibara and T. Suzuki: Chem. Rev. Vol. 95 (1995), p. 1409

[11] C. Wang, J. Wang, C.B. Park and Y.K. Kim: J. Mater. Sci. Vol. 42 (2007), p. 2854

[12] M. Narisawa, H. Yasuda, R. Mori, H. Mabuchi, K. Oka and Y.W. Kim: J. Ceram. Soc. Japan Vol. 116 (2008), p. 121 